\title{
Tardive dyskinesia in an 8-year old child
}

\author{
WMML Chandradasa, SW Kotalawala, GR Siriwardena, RML Champika, S Seneviratne, \\ H Perera
}

\section{Abstract}

Tardive dyskinesia (TD) is an uncommon presentation in children, which can be disabling and irreversible when it does occur. An 8 year old boy, with a diagnosis of autism spectrum disorder and borderline intelligence, developed features suggestive of TD on withdrawal of long-term haloperidol medication. After recommencing haloperidol at a lower dose his symptoms improved clinically and the Abnormal Involuntary Movement Scale score also decreased. Haloperidol was tailed off gradually and vitamin E was initiated.

Key words: tardive dyskinesia, children, haloperidol

SL J Psychiatry 2014; 5(2) 24-26

\section{Introduction}

Tardive Dyskinesia (TD) is a complex clinical entity of involuntary movements. TD includes choreiform, myoclonic and athetoid movements which affects lower face, limbs and trunks in $75 \%, 50 \%$ and $25 \%$ of patients respectively (1).

TD in children is not well described in the medical literature when compared to adults. This may be due to the fact that drug induced and organic aetiologies are more likely in adults. We present a case of TD in an 8 year old child. The objective is to describe the presenting features, aetiology and management, and discuss the importance of early recognition and prevention.

\section{Case report}

An 8 year old boy presented with disruptive behaviour. He was already on antipsychotic and stimulant therapy. The child has had extreme demanding behaviour with temper tantrums. The parents had been unable to set limits.

His difficulties in establishing friendships at school had made him isolated. He had odd interests such as collecting colour pencils, which he never used. His inability to remain seated for long, and frequent engagement in risk taking behaviours posed problems for his teachers. His academic performance was poor and he lagged behind in reading and writing. He required more supervision than was appropriate for his age when attending to activities of daily living.

Assessment revealed that he was suffering from autism spectrum disorder with hyperactivity (2). The Childhood Autism Rating Scale (CARS) indicated a mild severity of illness (3). Assessment using the Test of Non Verbal Intelligence showed borderline intelligence.

The child had been on antipsychotics over the last 3 years. Initially he was prescribed haloperidol at a cumulative dose of $9 \mathrm{mg}$ daily for 14-16 months, and thereafter risperidone for 3-6 months. Most recently, in the last 12-14 months, he was on haloperidol $15 \mathrm{mg}$ daily, cumulative dose, as the only antipsychotic agent. Since 1 year ago, he was also given benzhexol 4-6 mg daily.

The child had also been prescribed methylphenidate 15 mg daily for the last 2 years.

After assessment of the patient, haloperidol was tailedoff over a month, and parents were advised about the possible consequences. Methylphenidate was continued unchanged. Behavioural interventions with antecedent, behaviour and consequences (ABC) approach, limit setting and negative reinforcement, with involvement of the parents, were the mainstay of treatment.

In the fourth week after stopping haloperidol the child developed involuntary movements including pouting, smacking of lips and chewing. There were protrusions and twisting movements of the tongue. The child also developed choreiform movements of both upper limbs and squirming, inversion-extraversion movements of the lower limbs. A clinical diagnosis of TD was made. The Abnormal Involuntary Movement Scale (AIMS) score at this point was 19 (4).

After detailed assessment, it was concluded that the most likely cause for the development of TD was the withdrawal of the large dose of haloperidol, which the child had been taking for over a year.

The child was recommenced on a lower dose of haloperidol. He was also prescribed vitamin E. The child appeared to respond, and showed significant improvement in AIMS scores at 1-month follow-up and further improvement at 2-months.

\section{Discussion}

TD may occur in up to $30 \%$ of persons prescribed antipsychotic drugs. This may increase up to nearly 50\% 
in the elderly (5). The figures in children are less evident as large studies are limited.

Antipsychotics have been used for varying psychiatric ailments in children for more than 50 years. The available evidence of antipsychotic medication induced involuntary movements in children is few and far between. In most published cases, the movements have been reported to be transient (6). Studies suggest that first generation antipsychotics have a relatively higher risk of TD when used long-term $(7,8)$.

No strict criteria have been identified for the diagnosis of tardive dyskinesia. Schooler and Kane criteria describe 3 features, i.e., the use of antipsychotics at least for 3 months, involuntary movements of moderate intensity observed at least in one region or of mild intensity in at least two regions, and exclusion of other conditions that cause movement disorders (9). In this patient the initial two criteria were easily fulfilled and there were no features of other neurological disorders.

Use of a typical antipsychotic in higher doses and intellectual impairment (10) were the risk factors for development of TD in this child. He weighed $31 \mathrm{~kg}$ at initial assessment and was on haloperidol $480 \mathrm{mcg} / \mathrm{kg} /$ day. The usual recommended dose of haloperidol for children 3-12 years is, $50-150 \mathrm{mcg} / \mathrm{kg} /$ day given in divided doses (11).

Appearance of extra pyramidal symptoms early in the treatment and use of anticholinergic agents may also have contributed (10). Autism spectrum disorder itself may have been an additional risk factor for developing TD.

The possibility of methylphenidate induced dyskinetic movements (12) or motor tics (13) need to be considered in the differential diagnosis of TD in this child. But the fact that methylphenidate was continued for 2 years at the same dosage without development of any motor symptoms, the inability of the child to suppress the movements despite trying, the increase or persistence of movements at same level on distraction, and the absence of pre-monitory urge or tension makes this possibility less likely.

Another diagnosis to be considered would be immune mediated chorea. But there were no features suggestive of recent infections. The clear association with withdrawal of antipsychotics and improvement with recommencing of treatment is highly suggestive of antipsychotic induced TD.

Other differential diagnoses such as a cerebro-vascular accident, Wilson's disease, Huntington's disease are highly unlikely due to his age and absence of other features suggestive of these conditions.

Published data on TD in children are limited and evidence regarding treatment of TD in children is scarce. Therefore the management of this patient was guided by clinical experience and literature available for this condition in adults. Studies in adults have shown some benefit in prescribing vitamin $\mathrm{E}$ in higher doses of 400-1600 IU $(14,15)$. Benefits are thought to be due to the antioxidant effects of vitamin E. In view of this, the child was prescribed vitamin $\mathrm{E}$.

The development of TD, a potentially irreversible adverse effect of antipsychotics, in this child highlights the importance of holistic clinical decision making in child psychopharmacology. Prevention of TD depends on detailed assessment, rational diagnosis, use of psychological interventions and if necessary prescription of psychotropic medications at the lowest possible doses. All psychiatrists practicing child psychiatry should be alert to possibility of TD in children and take necessary steps to minimise the risk.

\section{Declaration of interest}

None declared

WMML Chandradasa, Faculty of Medicine, University of Kelaniya, Ragama, Sri Lanka

sW Kotalawala, GR Siriwardene, RML Champika, S Seneviratne

Lady Ridgeway Hospital for Children, Colombo, Sri Lanka

\section{Hemamali Perera}

Faculty of Medicine, University of Colombo, Sri Lanka

Corresponding author: WMML Chandradasa

Email:miyuruc@yahoo.com

\section{References}

1. Glazer WM, Morgenstern H, Niedzwiecki D, Hughes J. Heterogeneity of tardive dyskinesia. A multivariate analysis. Br J Psychiatry 1988; 152: 253-9.

2. American Psychiatric Association. Diagnostic and statistical manual of mental disorders (5th ed.). Washington, DC; American Psychiatric Association: 2013.

3. Schopler E, Reichler RJ, DeVellis RF, Daly K. Toward objective classification of childhood autism: Childhood Autism Rating Scale (CARS). J Autism Dev Disord 1980; 10: 91-103.

4. Simpson GM, Lee JH, Zoubok B, Gardos G. A rating scale for tardive dyskinesia. Psychopharmacology 1979; 64(2): 171-9.

5. Woerner MG, Alvir JM, Saltz BL, Lieberman JA, Kane JM. Prospective study of tardive dyskinesia in the elderly: rates and risk factors. Am J Psychiatry 1998; 155(11): 1521-8.

6. Silverstein FS, Johnston MV. Risks of neuroleptic drugs in children. J Child Neurol 1987; 2: 41-3.

7. Sejil I, Oumaya A, Bouguerra C, Mehdi F, Bellaaj R, Gallali $\mathrm{S}$. Tardive dyskinesia induced by classical antipsychotic drugs: a Tunisian sample of schizophrenics. Encephale 2013; 39(Suppl 1): S36-41. 
8. Gershanik OS, Gómez Arévalo GJ. Typical and atypical neuroleptics. Handb Clin Neurol 2011; 100: 579-99.

9. Schooler NR, Kane JM. Research diagnoses for tardive dyskinesia. Arch Gen Psychiatry 1982; 39(4): 486-7.

10. Eberhard J, Lindström E, Levander S. Tardive dyskinesia and antipsychotics: a 5-year longitudinal study of frequency correlates and course. Int Clin Psychopharmacol 2006; 21(1): 35-42.

11. Haloperidol: oral route. [Homepage on the internet]. Mayo Clinic c2014. Available at: http://www.mayoclinic.org/ drugs-supplements/haloperidol-oral-route/proper-use/drg20064173 (accessed October 2014).
12. Yilmaz AE, Donmez A, Orun E, Tas T, Isik B, Sonmez FM. Methylphenidate-induced acute orofacial and extremity dyskinesia. J Child Neurol 2013; 28(6): 781-3.

13. Palumbo D, Spencer T, Lynch J, Co-Chien H, Faraone SV. Emergence of tics in children with ADHD: impact of once-daily OROS methylphenidate therapy. J Child Adolesc Psychopharmacol 2004; 14(2): 185-94.

14. Egan MF, Hyde TM, Albers GW, et al. Treatment of tardive dyskinesia with vitamin E. Am J Psychiatry 1992; 149(6): 773-7.

15. Adler LA, Peselow E, Rotrosen J, et al. Vitamin E treatment of tardive dyskinesia. Am J Psychiatry 1993; 150(9): 1405-7. 